\title{
Changes before and after improvement of subjective sleep state of a man diagnosed with pre-diabetes and sleep disorder
}

\author{
Miki Sato $^{1^{*}}$, Yuko Yasuhara ${ }^{2}$, Tetsuya Tanioka ${ }^{2}$, Yukie Iwasa ${ }^{2}$, Toshiyuki Yasui ${ }^{2}$, \\ Masafumi Miyake ${ }^{3}$, Haruo Kobayashi ${ }^{4}$, Waraporn Kongsuwan ${ }^{5}$, Rozzano C. Locsin ${ }^{6}$ \\ ${ }^{1}$ Department of Nursing, Faculty of Nursing, Shikoku University, Tokushima, Japan; \\ *Corresponding Author: msato@shikoku-u.ac.jp \\ ${ }^{2}$ Department of Nursing, Institute of Health Biosciences, The University of Tokushima Graduate School, Tokushima, Japan \\ ${ }^{3}$ Tokushima Prefectural Minami Health Care Center, Tokushima, Japan \\ ${ }^{4}$ Faculty of Medical Welfare, Kawasaki University of Medical Welfare, Kurashiki, Japan \\ ${ }^{5}$ Department of Medical Nursing, Faculty of Nursing, Prince of Songkla University, Songkhla, Thailand \\ ${ }^{6}$ Christine E. Lynn College of Nursing, Florida Atlantic University, Boca Raton, USA
}

Received 16 January 2013; revised 22 February 2013; accepted 3 March 2013

\section{ABSTRACT}

The purpose of this case study was to examine the changes before and after improvements of the subjective sleep status of Mr. A in his 40s diagnosed with pre-diabetes and a sleep disorder. Data were collected using a Holter monitor for 24 hours a day for 3 days to assess autonomic nervous activity by recording bed- time and waking time activity (activity counts: ACs). Mr. A kept a diary of activities and com- pleted the Pittsburgh Sleep Quality Index (PSQI) questionnaire. The study revealed that subjec- tive sleeping hours correlated almost precisely with those measured by the actigraph and as described in the diary. Both the parasympathetic and sympathetic nervous system activities were imbalanced. However, no correlation was observed between the ACs and autonomic nervous activity. According to the PSQI, subjective sleep state score improved remarkably by dietary and exercise therapy from 13 to 3 points, and after six months, with corresponding high level turned to sleep satisfaction level. Significant correlations were observed between ACs and highfrequency spectral power of R-R intervals, and between $A C s$ and the low-frequency/high frequency ratio of spectral power of $R-R$ intervals. Although Mr. A's sleep satisfaction level has improved, the autonomic nervous system activity remained different from that of healthy people.

Keywords: Actigraphy; Heart Rate Variability;
Autonomic Nervous System; Function; Disturbed sleep; Pre-Diabetes

\section{INTRODUCTION}

The autonomic nervous system involves double innervation comprised of both the sympathetic and parasympathetic nervous systems. These nervous systems balance each other and maintain a constant condition such that daytime, nighttime, and sleeping state activities can switch naturally $[1,2]$. Autonomic nervous system activity can be evaluated in various ways [1,3] such as heart rate variability (HRV) which can be non-invasively determined and used, especially to determine the balance between parasympathetic and sympathetic nervous system activities [4]. Actigraphy is a non-invasive watchshaped monitor that can be used to assess the balance between hours of activity/sleep and the conditions of sleep disturbance [5]. Although one study has analyzed actigraph findings and HRV [6], little is known about the correlation between actigraph findings and HRV.

The morbidity rates of individuals with either diabetes or hypertension and sleep disturbance are high [7], and sleep disturbances notably increase blood glucose levels and blood pressure [8]. Furthermore, a lack of sleep causes a decrease in glucose tolerance and an increase in appetite [9], and also increases the risk of various life-style related diseases $[10,11]$.

Decreased HRV in diabetic patients has been confirmed in studies. HRV apparently decreases before diabetic autonomic neuropathy appears clinically, and it further decreases if autonomic neuropathy is confirmed; thus, HRV is considered the most accurate indicator of 
this condition $[12,13]$. Long or short sleep durations are risk factors for diabetes $[14,15]$, and a decrease in the quality of sleep may exacerbate blood sugar control [16]. Therefore, evaluating blood glucose levels as well as disturbance, duration, and quality of sleep is important for improving early detection of diabetic autonomic neuropathy.

This case study was aimed to explore the changes before and after improvement in the subjective sleep state in a man with pre-diabetes and a sleep disorder by analyzing the association between activity counts (ACs) on actigraphs and autonomic nervous activity.

\section{METHODS}

\subsection{Definition of Technical Terms}

1) Low Frequency (LF): The LF component (0.04 $0.15 \mathrm{~Hz}$ ) was extracted with power spectrum density and reflects the variable of the electrocardiographic R-R interval, which is affected by activities of the sympathetic and parasympathetic nervous systems.

2) High Frequency (HF): The high frequency component $(0.15-0.50 \mathrm{~Hz})$ was extracted as above and serves as an indicator of parasympathetic nervous system activity.

3) $L F / H F$ ratio: The $L F / H F$ ratio is an indicator of sympathetic nervous system activity.

4) ACs on actigraphs: ACs on actigraphs indicate the amount of activity exceeding $0.01 \mathrm{G} / \mathrm{min}$ during an epoch of 1 min measured by actigraphy. $\mathrm{G}$ is gravitational acceleration $\left(9.8 \mathrm{~m} / \mathrm{sec}^{2}\right)$.

5) Up and down intervals on actigraphs: These are periods during which the patient wears actigraphs and are divided into "up" (daytime activity) intervals, defined as the period of time patient reported being out of bed, and "down" (sleep) intervals, defined as the period during which patient was in bed.

\subsection{Measurement Methods}

1) Holter electrocardiography: The patient also wore a Holter electrocardiograph for a period of 24 hours.

2) Actigraph: A micro mini-type actigraph (Ambulatory Monitoring, Inc. Ardsley, NY, USA) was attached on his non-dominant arm for 3 days starting from 18:00 on the first day.

3) Diary: Mr. A kept a daily log of the time he awoke in the morning and went to bed, as well as descriptions of meals, work, and exercise for 3 consecutive days.

4) Pittsburgh Sleep Quality Index (PSQI): The patient completed the Japanese version of the PSQI (PSQI-J) [17] on the final day of the study. The PSQI-J comprises 18 items and 7 factors in total and a scale from 1 to 5 that gathers information about the quality of sleep and sleeping habits over the previous month.

\subsection{Methods of Analysis}

1) The data obtained from the actigraph were analyzed using AW2 software (Ambulatory Monitoring Inc., Ardsley, NY, USA). Sleep duration (Dur), wake time in bed (Wmin), sleep time in bed (Smin), percentage of sleep (Pslp) and sleep efficiency (Seff) were measured using the actigraph records from July 20XX (without sleeping medication and with sleeping medication) and December 20XX (after improvement in sleep disturbance).

2) Time series data of interbeat (RR) intervals were formalized from an FM180 electrocardiograph (Fukuda Denshi Co. Ltd., Tokyo, Japan) using Holter software (Fukuda Denshi Co. Ltd.), and the HRV was analyzed using Mem Calc/CHIRAM (GMS Co., Tokyo, Japan).

3) The sleep condition was assessed using both the actigraph and the HRV analyzer during the post-measurement interview with the patient. The HRV data and ACs produced over 5-min intervals were matched.

4) The analyzed actigraph data by AW2 software at three measurement points: July 20XX, without sleeping medication and with sleeping medication, and December 20XX; after improvement in sleep disturbance, are exhibited in Table 1.

5) Correlations between ACs and parasympathetic/ sympathetic nervous system activities were analyzed using Pearson's product-moment correlation coefficient.

6) Differences between average values of parasympathetic nervous system activity during the daytime and while asleep, and between average values of sympathetic nervous system activity in the daytime and while asleep were analyzed using an unpaired $t$-test.

\subsection{Data Collection and Description of the Participant}

Using Actigraphy and the HRV Analyzer, data were measured a total of three times, i.e. twice (with and without a sedative drug) in July 20XX; and one time in December 20XX after improvement in the subject's sleep disorder.

A married male patient in his 40s (Mr. A) with pre-diabetes who was diagnosed with a sleep disturbance was the subject of the study. Mr. A presented in July 20XX. He was $167 \mathrm{~cm}$ tall and weighed $65 \mathrm{~kg}$, with a body mass index (BMI) of $23.3 \mathrm{~kg} / \mathrm{m}^{2}$. He had an HbAlc level (Japan Diabetes Society) of 5.9\%, showed symptoms of a sleep disorder (PSQI-J score of 13 points), and was taking a hypnotic before bed (brotizolam: lendormin $\mathrm{D}$ tablets $0.25 \mathrm{mg}$ ). Exercise and diet therapy resulted in improvement in the sleep disturbance in September, $20 \mathrm{XX}$, and he no longer needed to take the sleeping medication. As of December 20XX, he weighed $69 \mathrm{~kg}$, with a BMI of $24.7 \mathrm{~kg} / \mathrm{m}^{2}$. He had an HbAlc level of 
Table 1. Comparison of results of sleep conditions by actigraph data.

\begin{tabular}{cccc}
\hline & \multicolumn{2}{c}{ July 20XX } & December 20XX \\
\hline & $\begin{array}{c}\text { With sleeping } \\
\text { medication }\end{array}$ & $\begin{array}{c}\text { Without sleeping } \\
\text { medication }\end{array}$ & $\begin{array}{c}\text { After improvement } \\
\text { in sleep disturbance }\end{array}$ \\
Dur (min) & 390 & 397 & 426 \\
Wmin (min) & 3 & 25 & 14 \\
Smin (min) & 387 & 372 & 412 \\
Pslp (\%) & 99.23 & 93.7 & 96.71 \\
Seff (\%) & 99.74 & 93.7 & 99.03 \\
\hline
\end{tabular}

Dur (from bed time to waking); Wmin (wake time in bed); Smin (sleep time in bed); Pslp (percentage of sleep); Seff (sleep efficiency).

$6.0 \%$, and he slept well without taking any sleeping medication (PSQI-J score of 3 points).

\subsection{Ethical Considerations}

The data were managed according to the Private Information Protection Law, with approval by the Tokushima University Hospital Ethics Board (Approval number 1558) and the cooperation of the hospital staff. A member of the interdisciplinary team obtained written informed consent from Mr. A and his family after he received an explanation of the study. He was assured that his personal information would be protected, and used only for research purposes.

\section{RESULTS}

Table 1 shows the Dur of $390 \mathrm{~min}$, as determined by the actigraph in July 20XX. The Wmin was $3 \mathrm{~min}$, and the Smin was 387 min, indicating a Seff of $99.74 \%$.

As determined by the actigraph on days when no sleeping medication was taken in July 20XX, the Dur was $397 \mathrm{~min}$. The Wmin was $25 \mathrm{~min}$, and the Smin was 372 min, indicating a Seff of $93.70 \%$.

As determined by the actigraph in December 20XX, the Dur was $426 \mathrm{~min}$. The Wmin was $14 \mathrm{~min}$, and the Smin was $412 \mathrm{~min}$, indicating a Seff of $99.03 \%$.

Table 2 shows that when sleeping medication was taken in July 20XX, the daytime HF of $140.57 \pm 84.96$ $\mathrm{msec}^{2}$ was not significantly different from the HF of $138.56 \pm 102.59 \mathrm{msec}^{2}$ during sleep $(t=0.15 ; \mathrm{df}=$ $119.56 ; \mathrm{p}=0.88$ ). The daytime LF/HF of $5.50 \pm 2.82$ was also significantly different from the sleep LF/HF of $8.49 \pm 6.31(t=4.03 ; \mathrm{df}=89.01 ; \mathrm{p}<0.001)$.

When no sleep medication was taken in July 20XX, the daytime HF of $205.29 \pm 131.03 \mathrm{msec}^{2}$ was significantly higher than the HF of $125.77 \pm 85.11 \mathrm{msec}^{2}$ during sleep $(t=5.94 ; \mathrm{df}=222.05 ; \mathrm{p}<0.001)$. The LF/HF of $5.71 \pm 3.62$ during sleep was not significantly higher than the daytime LF/HF of $8.42 \pm 6.59(t=3.47$; df $=$ 99.25; $\mathrm{p}<0.001)$.

After improvement in sleep disturbance in December 20XX, the daytime HF of $302.80 \pm 184.41 \mathrm{msec}^{2}$ was significantly higher than the HF of $80.10 \pm 47.08 \mathrm{msec}^{2}$ during sleep $(t=15.88 ; \mathrm{df}=249.04 ; \mathrm{p}<0.001)$. The $\mathrm{LF} / \mathrm{HF}$ of $5.39 \pm 2.07$ during sleep was also significantly higher than the daytime LF/HF of $9.74 \pm 7.94(t=4.97$; $\mathrm{df}=$ 99.92; $\mathrm{p}<0.001$ ).

Figure 1 shows the results when sleeping medication was used in July 20XX. Subjective sleeping time was consistent with sleeping time as assessed by the actigraph.

The HF increased, although not continuously, starting 90 min after the sleeping medication was taken (11:00 PM) and increased repeatedly every hour, with a peak time lasting less than about 1 hour. The HF decreased 2 hours before waking (4:00 AM). During the day, the level fluctuated, increasing at 10:00 AM and from 4:00 PM to 6:00 PM. No positive correlation was found between actigraph ACs and HF $(r=-0.072 ; N S)$. The LF/HF began to increase gradually about 3 hours before waking (4:00 AM) and fluctuated mildly during the day. There was no apparent correlation between actigraph ACs and LF/HF $(r=-0.148 ; N S)$.

Table 2. Comparison of autonomic nervous activity while awake and while asleep.

\begin{tabular}{|c|c|c|c|c|c|c|}
\hline Measurement timepoint & $\begin{array}{l}\text { Autonomic nervous } \\
\text { activity }\end{array}$ & $\begin{array}{c}\text { Up interval } \\
\text { (day time activity) }\end{array}$ & Down interval (sleep) & $t$ & $d f$ & $p$ \\
\hline \multirow[t]{2}{*}{ July, 20XX: With sleeping medication } & $\mathrm{HF}$ & $140.57 \pm 84.96$ & $138.56 \pm 102.59$ & 0.15 & 119.56 & NS \\
\hline & $\mathrm{LF} / \mathrm{HF}$ & $5.50 \pm 2.82$ & $8.49 \pm 6.31$ & 4.03 & 89.01 & *** \\
\hline \multirow[t]{2}{*}{ July, 20XX: Without sleeping medication } & $\mathrm{HF}$ & $205.29 \pm 131.03$ & $125.77 \pm 85.11$ & 5.94 & 222.05 & $* * *$ \\
\hline & $\mathrm{LF} / \mathrm{HF}$ & $5.71 \pm 3.62$ & $8.42 \pm 6.59$ & 3.47 & 99.25 & *** \\
\hline \multirow[t]{2}{*}{$\begin{array}{l}\text { December, 20XX: After improvement in } \\
\text { sleep disturbance }\end{array}$} & $\mathrm{HF}$ & $302.80 \pm 184.41$ & $80.10 \pm 47.08$ & 15.88 & 249.04 & *** \\
\hline & $\mathrm{LF} / \mathrm{HF}$ & $5.39 \pm 2.07$ & $9.74 \pm 7.94$ & 4.97 & 92.93 & *** \\
\hline
\end{tabular}

${ }^{* * *} \mathrm{p}<0.001, \mathrm{NS}=$ not significant, HF (High Frequency) $\mathrm{msec}^{2}$, LF/HF LF (Low Frequency)/HF ratio, Up interval (minus sleep time from 6 PM at start of measurement to $6 \mathrm{PM}$ on following day). 


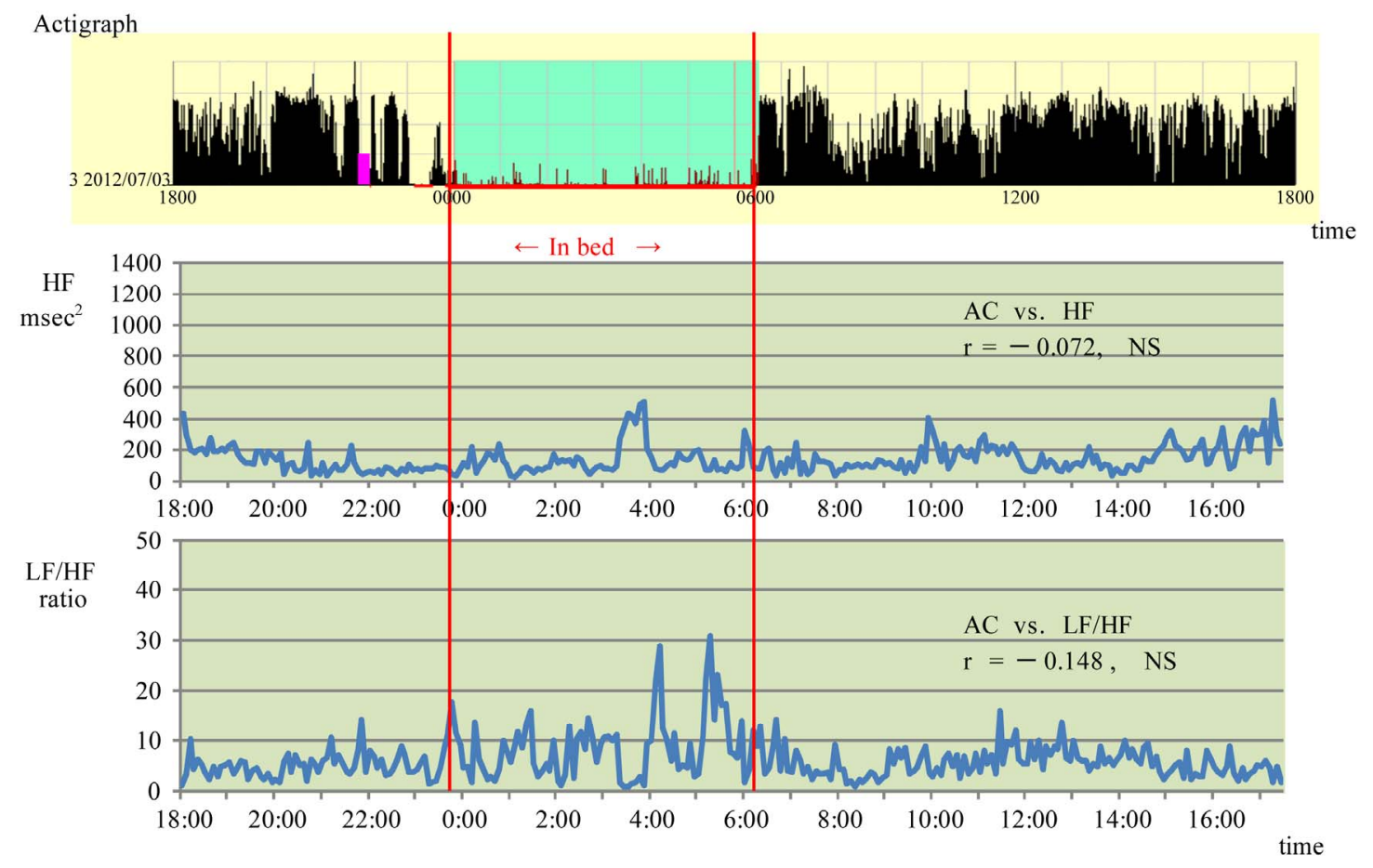

Figure 1. Association between activity counts and parasympathetic and sympathetic nervous system activity while taking a sleeping pill in July 20XX. HF: high frequency, LF: low frequency, AC: activity count, Red lines show sleep time.

Figure 2 shows the results when the patient consented to not use the sleeping medication during the same period in July 20XX. HF peaked at 12:15 AM. It fluctuated during the day, and increased from 10:00 AM to 1:00 PM, with no differences between day and night. The patient complained of sleepiness during the day. A weak positive correlation was found between actigraph ACs and HF $(r=0.261 ; \mathrm{p}<0.01)$.

The LF/HF fluctuated considerably during sleep. From 2:00 to 3:00 $\mathrm{AM}$, the activity count increased, indicating that the patient awoke at night. There was virtually no fluctuation during the day. Virtually no correlation was found between actigraph ACs and LF/HF $(r=-0.142$; $N S$ ).

Figure 3 shows the data obtained during the improved subjective sleeping state after improvement in the sleeping disturbance in December 20XX.

A positive correlation was found between actigraph ACs and HF $(r=0.342 ; \mathrm{p}<0.01)$. A weak negative correlation was found between actigraph ACs and LF/HF ( $r$ $=-0.331 ; \mathrm{p}<0.01)$.

\section{DISCUSSION}

The PSQI is an internationally standardized scale [18], and the Japanese version (Cronbach $\alpha=0.77$ ) is reliable and appropriate for assessing the lack and subjective quality of sleep [17]. The cut-off for poor-quality sleep is regarded as above 6 points $[17,19]$.
Comparison of the score prevailing at the time of the patient's sleep disturbance in July 20XX with that during December 20XX, when the patient experienced improvement in subjective sleep, revealed a decrease in the Pittsburgh sleep score from 13 to 3 points, which represented improvement beyond the cut-off of 6 points and was consistent with the patient's sense that he was sleeping better even without the use of a sleeping aid.

As determined by the actigraph on days when no sleeping medication was taken in July 20XX, the sleep time was 397 min ( 6.6 hours). The Wmin of 25 min was 23 min longer than when sleeping medication was used, the Smin of 372 min was 5 min shorter than when sleeping medication was used, and the sleeping efficiency of $93.7 \%$ was $6.04 \%$ lower than when sleeping medication was used. Additionally, in interviews based on the diary of activities, the patient complained of discomfort due to waking up during the night and severe sleepiness during the day. The parasympathetic nervous system also became active from 3:00 AM to 4:00 AM when the patient took sleeping medication, whereas no activation of the parasympathetic nervous system during sleep was observed when no sleeping medication was taken.

The parasympathetic nervous system was also active during the day when the patient had taken no sleeping medication; sleepiness during the daytime was consistent with parasympathetic activation during the daytime (10 AM to 1 PM). Lindholm et al. [20] suggested that ir- 


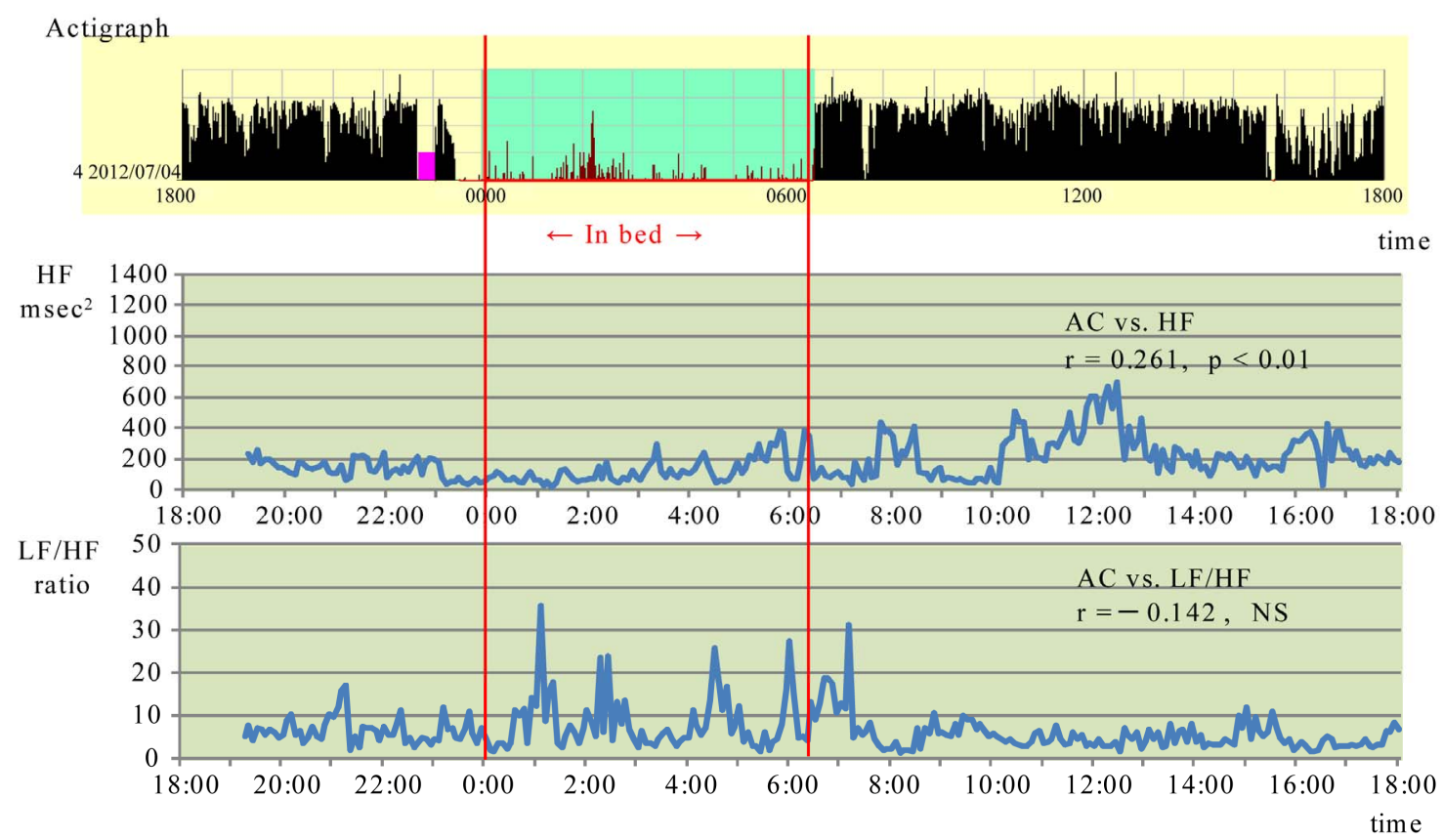

Figure 2. Association between activity counts and parasympathetic and sympathetic nervous system activity without a sleeping pill in July 20XX. HF: high frequency, LF: low frequency, AC: activity count, Red lines show sleep time.

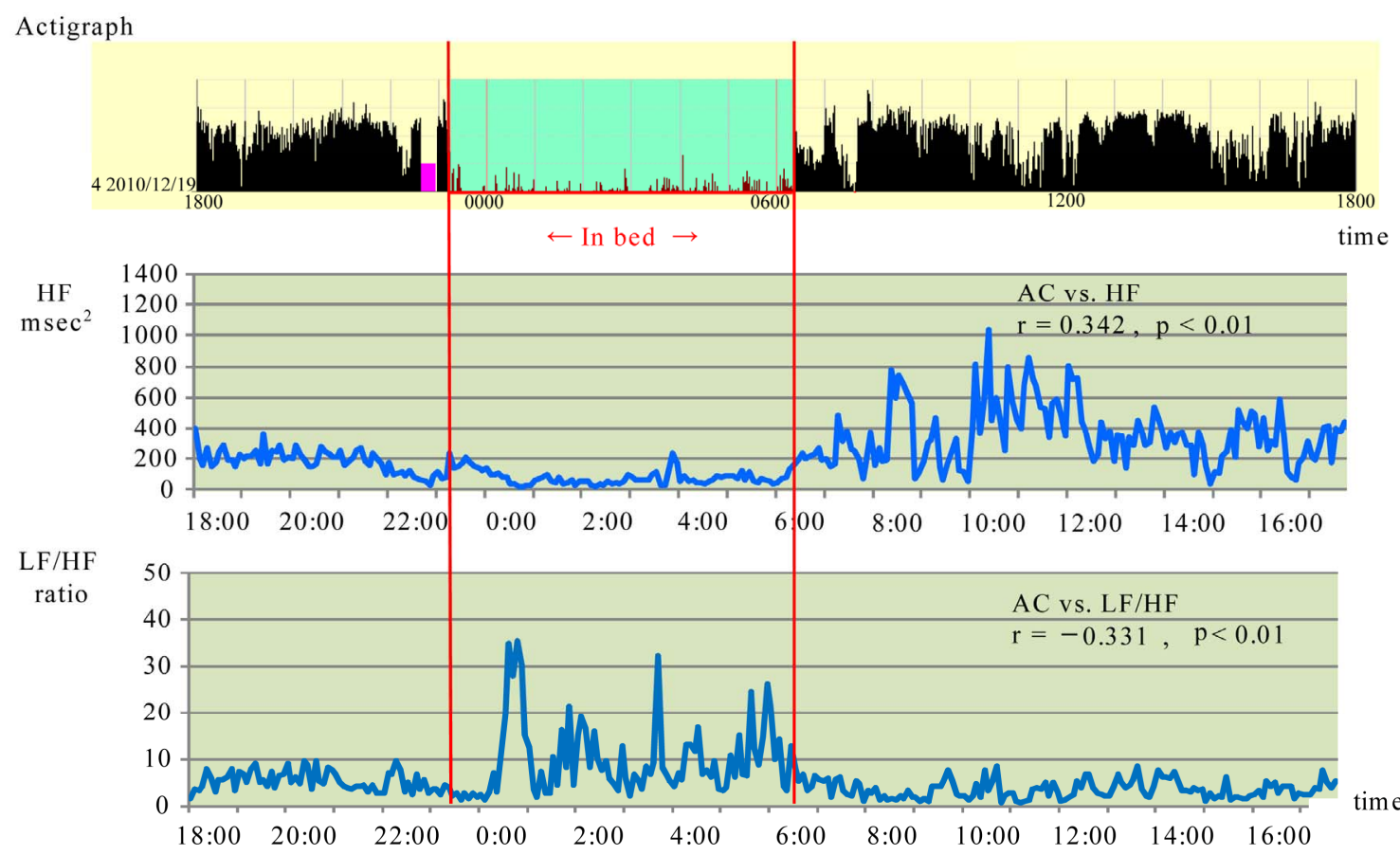

Figure 3. Association between activity counts and parasympathetic and sympathetic nervous system activity after improved sleep disorder in December 20XX. HF: high frequency, LF: low frequency, AC: activity count, Red lines show sleep time.

regular shift work increased the risk of insufficient recovery when compared to normal daytime work. Attenuated HRV during sleep reflects prolonged sympathetic drive and/or impaired parasympathetic recovery.

Subjective sleep estimates correlated to self-reported daytime consequences such as fatigue and concentration difficulty but not cognitive function. Therefore such people may experience such a daytime symptom as fatigue although cognitive function remains unimpaired [21].

From these results, it could be summarized that the 
sleeping drug for sleep disorder might be an important reason for the recovery of the parasympathetic activities.

Decreased HRV on 24-hour ECG, which is considered a cardiovascular risk, is caused primarily by nocturnal decreases in vagal function and could possibly reflect resting function failure [22]. Also, a respiratory sinus arrhythmia has received much attention in recent years due to the large body of evidence indicating that variations in this phenomenon represent alterations in parasympathetic cardiac control [23].

Acute psychophysiological stress was associated with decreased levels of parasympathetic modulation during nonrapid eye movement (NREM) and rapid eye movement sleep and increased levels of sympathovagal balance during NREM sleep. Changes in heart rate variability associated with acute stress may represent one pathway to disturbed sleep. Stress-related changes in heart rate variability during sleep may also be important in association with chronic stressors, which are associated with significant morbidity and increased risk for mortality [24].

Although subjective sleep disorder has improved, the remarkable improvement was not observed in HRV. When balance with the parasympathetic nerve is confused by stimulus of hyperglycemia, stress, etc., it becomes impossible to control the body and mind normally. Therefore, for a further improvement of autonomic nerve activity, not only diabetes but also stress control is considered to be an important point.

As determined by the actigraph in December 20XX, the Dur was 426 min (7.1 hours), which was $22 \mathrm{~min}$ longer than when sleeping medication was taken. The wmin of 14 min was 11 min longer than when sleeping medication was used, the smin of $412 \mathrm{~min}$ was $25 \mathrm{~min}$ longer than when sleeping medication was used, and the sleeping efficiency of $99.03 \%$ was $0.71 \%$ lower than when sleeping medication was used.

In studies on sleep duration and the risk of developing diabetes [25,26], a U-shaped distribution of relative risk was reported for groups with short and long sleep duration versus a 7-hour sleep group. Studies on the relationship between sleep quality and risk of diabetes [1315] have also reported a high risk for developing diabetes in groups with a high incidence of trouble falling asleep or waking at night, suggesting that disturbances in sleeping habits may result in a higher risk for developing diabetes.

This case was characterized by short sleep duration despite the use of sleeping medication for sleep disturbance. When no sleeping medication was taken, the patient suffered from poor quality sleep because, in addition to short sleep duration, he also woke up at night and felt sleepy during the day. The short sleep duration also put him at high risk for developing diabetes.
A study on the relationship between HbAlc levels and sleep duration reported that short or long sleep duration is associated with a high proportion of diabetic levels of HbA1c (JDS level) $\geq 6.5 \%$ [26]. It has been pointed out that sleep and circadian rhythm disorders are found in diabetic patients, and that higher fasting blood glucose levels and HbAlc levels are related to major sleep and circadian rhythm disturbances [27]. Because of the lack of change in HbAlc levels $(5.9 \%$ to $6.0 \%)$ even when this patient experienced subjective improvement in sleep disturbance, exercise and diet therapy will need to be continued in the future for further analysis of the relationship between sleep state and diabetes pathology.

In addition, a review of the results for HRV revealed no significant sympathetic/parasympathetic differences between waking and sleeping while sleep medication was taken in July 20XX. During both waking and sleeping when no sleeping medication was taken in July and in December, autonomous nervous activity was paradoxically predominant during waking and sleeping, with sympathetic activation during sleep and parasympathetic activation during waking. Our research to date has shown that in healthy adults [28], parasympathetic nervous activity predominates during sleep, whereas the sympathetic nervous system is activated during waking, with a strong correlation between $\mathrm{AC}$ and $\mathrm{HF}$ as well as between $\mathrm{AC}$ and $\mathrm{LF} / \mathrm{HF}$. In the present case, when the patient suffered from sleep disturbance, these correlations were weaker. A correlation was found in December, when the man felt there had been improvement in sleep disturbance, but both correlations were weaker. When subjective sleep improves, it may take some time for changes to appear as HRV.

Physical exercise has beneficial physical and mental effects, suggesting the possibility of mental and physical interactions [29]. It may be important to continue to monitor this patient's progress by guiding lifestyle choices, developing appropriate weight management, and regularly scheduling eating and activities.

It will be necessary to study more patients in the future to find out whether these results are limited to this one person or are similar to those in other borderline patients. Despite improvement in subjective sleep disturbance, analysis of HRV showed no significant changes. After appropriate guidance regarding lifestyle choices has been provided and there has been some improvement in HbAlc and BMI, the assessments employed in this study should be done again to study the usefulness of such assessments based on actigraphs and autonomous nervous activity.

\section{CONCLUSION}

In this study, the changes before and after improvements of the subjective sleep status of Mr. A in his 40s 
diagnosed with pre-diabetes and a sleep disorder were examined using the PSQI score subjectively and objectively by using the data from actigraphy/electrocardiography. The subjective sleeping duration data correlated almost precisely with those measured by the actigraph as described in the diary. When subjects had sleep disorders the parasympathetic and sympathetic nervous system activities were imbalanced. The subjective data exhibited by the PSQI score showed that the participant had improved remarkably after six months, and subsequently his sleep satisfaction level became high. Although significant correlations were observed between ACs and HF, and between ACs and LF/HF, the HRV changes were evidently different from that of healthy people.

\section{CONFLICT OF INTERESTS}

None of the authors have any conflicts of interest to declare.

\section{REFERENCES}

[1] Burgess, H.J., Trinder, J. and Kim, Y. (1999) Cardiac autonomic nervous system activity during presleep wakefulness and stage 2 NREM sleep. Journal of Sleep Research, 8, 113-122. doi:10.1046/j.1365-2869.1999.00149.x

[2] Sherwood, A., Routledge, S., Wohlgemuth, W.K., Hinderliter, A.L., Kuhn, C.M. and Blumenthal, J.A. (2011) Blood pressure dipping: Ethnicity, sleep quality, and sympathetic nervous system activity, American Journal of Hypertension, 24, 982-988. doi:10.1038/ajh.2011.87

[3] Niwa, F., Kuriyama, N., Nakagawa, M. and Imanishi, J. (2011) Circadian rhythm of rest activity and autonomic nervous system activity at different stages in Parkinson's disease. Autonomic Neuroscience, 165, 195-200. doi:10.1016/j.autneu.2011.07.010

[4] Gih, S.C., Byoung, H.C., Do-Un, J. and Park, K.S. (2007) Noninvasive heart rate variability analysis using load-cellinstalled bed during sleep. Proceedings of the 29th NNUAL International Conference of the IEEE EMBS, Lyon, 23-26 August 2007, 2357-2360.

[5] Lewicke, A.T., Sazonov, E.S. and Schuckers, S.A. (2004) Sleep-wake identification in infants: Heart rate variability compared to actigraphy. Proceedings of the 26th NNUAL International Conference of the IEEE EMBS, San Francisco, 1-5 September 2004, 442-445.

[6] Grap, M.J., Borchers, C.T., Munro, C.L., Elswick Jr., R.K. and Sessler, C.N. (2005) Actigraphy in the critically ill: Correlation with activity, agitation, and sedation. American Journal of Critical Care, 14, 52-60.

[7] Budhiraja, R., Roth, T., Hudgel, D.W., Budhirai, P. and Drake, C.L. (2011) Prevalence and polysomnographic correlates of insomnia comorbid with medical disorders. Sleep, 34, 859-867.

[8] Loredo, J.S., Ancoli-Israel, S. and Dimsdale, J.E. (2001)
Sleep quality and blood pressure dipping in obstructive sleep apnea. American Journal of Hypertension, 14, 887892. doi:10.1016/S0895-7061(01)02143-4

[9] Touma, C. and Pannain, S. (2011) Does lack of sleep cause diabetes? Cleveland Clinic Journal of Medicine, 78, 549-558. doi:10.3949/ccjm.78a.10165

[10] Gangwisch, J.E., Malaspina, D., Boden-Albala, B. and HeymsField, S.B. (2005) Inadequate sleep as a risk factor for obesity: Analyses of the NHANES I. Sleep, 28, 12891296.

[11] Penev, P.D. (2012) Update on energy homeostasis and insufficient sleep. Journal of Clinical Endocrinology and Metabolism, 97, 1792-1801. doi:10.1210/jc.2012-1067

[12] Ewing, D.J., Campbell, I.W., Murray, A., Neilson, J.M. and Clake, B.F. (1978) Immediate heart-late response to standing simple test for autonomic neuropathy in diabetes. British Medical Journal, 1, 145-147. doi:10.1136/bmj.1.6106.145

[13] Chun, M.Y., Park, H.K., Hwang, H.S., Han, J.I., Chee, Y.J. and Lee, J.S. (2011) The Association between symptoms of autonomic neuropathy and the heart rate variability in diabetics. Korean Journal of Family Medicine, 32, 292298. doi:10.4082/kjfm.2011.32.5.292

[14] Nilsson, P.M., Rööst, M., Enqström, G., Hedblad, B. and Berglund, G. (2004) Incidence of diabetes in middle-aged men is related to sleep disturbances. Diabetes Care, 27, 2464-2469. doi:10.2337/diacare.27.10.2464

[15] Kawakami, N., Takatsuka, N. and Shimizu, H. (2004) Sleep disturbance and onset of type 2 diabetes. Diabetes Care, 27, 282-283. doi:10.2337/diacare.27.1.282

[16] Knutson, K.L., Ryden, A.M., Mander, B.A. and Van Cauter, E. (2006) Role of sleep duration and quality in the risk and severity of type 2 diabetes mellitus. Archives of Internal Medicine, 166, 1768-1774. doi:10.1001/archinte.166.16.1768

[17] Doi, Y., Minowa, M., Uchiyama, M., Okawa, M., Kim, K., Shibui, K. and Kamei, Y. (2000) Psychometric assessment of subjective sleep quality using the Japanese version of the Pittsburgh Sleep Quality Index (PSQI-J) in psychiartric disordered and control subjects. Psychiatry Research, 97, 165-172. doi:10.1016/S0165-1781(00)00232-8

[18] Shochat, T., Tzischinsky, O., Oksenberg, A. and Peled, R. (2007) Validation of the Pittsburgh Sleep Quality Index, Hebrew translation (PSQI-H) in a sleep clinic sample. $I s$ rael Medical Association Journal, 9, 853-856.

[19] Buysse, D.J., Reynolde, C. F., Monk, T.H., Beman, S.R. and Kupfer, D.J. (1989) The Pittsburgh Sleep Quality Index: A new instrument for psychiatric practice and research. Psychiatry Research, 28, 198-213. doi:10.1016/0165-1781(89)90047-4

[20] Lindholm, H., Sinisalo, J., Ahlberg, J., Hirvonen, A., Hublin, C., Partinen, M. and Savolainen, A. (2012) Attenuation of vagal recovery during sleep and reduction of cortisol/melatonin ratio in late afternoon associate with prolonged daytime sleepiness among media workers with irregular shift work. American Journal of Industrial Medicine, 55, 643-649. doi:10.1002/ajim. 22042

[21] Fang, S.C., Huang, C.J., Yang, T.T. and Tsai, P.S. (2008) 
Heart rate variability and daytime functioning in insomniacs and normal sleepers: preliminary results. Journal of Psychosomatic Research, 65, 23-30. doi:10.1016/i.jpsychores.2008.02.003

[22] Malpas, S.C. and Purdie, G.L. (1990) Circadian variation of heart rate variability. Cardiovascular Research, 24, 210-213. doi:10.1093/cvr/24.3.210

[23] Grossman, P., Karemaker, J. and Wieling, W. (1991) Prediction of tonic parasympathetic cardiac control using respiratory sinus arrhythmia: The need for respiratory control. Psychophysiology, 28, 201-216. doi:10.1111/j.1469-8986.1991.tb00412.x

[24] Hall, M., Vaako, R., Buysse, D., Ombao, H., Chen, Q., Cashmere, J.D., Kupfer, D. and Thayer, J.F. (2004) Acute stress affects heart rate variability during sleep. Psychosomatic Medicine, 66, 56-62. doi:10.1097/01.PSY.0000106884.58744.09

[25] Yaggi, H.K., Araujo, A.B. and McKinlay, J.B. (2006) Sleep duration as a risk factor for the development o type 2 diabetes. Diabetes Care, 29, 657-661. doi:10.2337/diacare.29.03.06.dc05-0879

[26] Nakajima, H., Kaneita, Y., Yokoyama, E., Harano, S., Tamaki, T., Ibuka, E., Kaneko, A., Takahashi, I., Umeda, T., Nakaji, S. and Ohida, T. (2008) Association between sleep duration and hemoglobin A1c level. Sleep Medicine, 9, 745-752. doi:10.1016/j.sleep.2007.07.017

[27] Tsujimura, T., Matsuo, Y., Keyaki, T., Sakurada, K. and Imanishi, J. (2009) Correlations of sleep disturbance with the immune system in type 2 diabetes mellitus. Diabetes Research and Clinical Practice, 85, 286-292. doi:10.1016/j.diabres.2009.07.001

[28] Sato, M., Iwasa, Y., Yasuhara, Y., Fujimoto, A., Ikekita, Y., Manabe, M., Tanioka, T., Yasui, T. and Kobayashi, H. (in press) Characteristics of autonomic nervous system activity and daily activity of females with sleep disturbance, diabetes or dementia in their late middle to old age.

[29] Fujibayashi, M., Umeda, Y., Matsumoto, T. and Moritani, T. (2011) Influence of physical exercise on psychosomatic health. Japanese Journal of Psychosomatic Medicine, 51, 336-344. 